\title{
Statistical Modelling of Comorbidity Effect on Second Cancer
}

\author{
${ }^{*}$ E. S. Oguntade and 2D. M. Oladimeji \\ 1Department of Statistics, Faculty of Science, University of Abuja \\ ${ }^{2}$ WHO Action Trial Site, University of Abuja Teaching Hospital Gwagwalada \\ [Corresponding Author: E-mail: oguntadeemmanuel2015@gmail.com; 8:+2347034996677]
}

\section{ABSTRACT}

Second cancer is a new cancer that occurs in someone who had history of cancer. The incidence of cancer is on the increase in the global scene and especially in Sub-Saharan Africa. This phenomenon constitutes huge health problems especially with comorbidity effects with other health conditions which have made the diagnosis and treatment of cancer patients a complex issue. Hence, this study determined the comorbidity effect on second cancer based on a retrospective study of 474 patients attending University of Abuja Teaching Hospital (UATH). These patients were first treated of cancer, and after one year developed another cancer or cancer free. The results revealed that the incidence of second cancer was approximately $39.5 \%$ and $41.4 \%$ of the patients with one or more other disease(s) had second cancer. Adjusted and unadjusted odds ratio from logistic regression showed that patients with history of smoking were 3.58 times more likely to develop second cancer when no adjustment was made to the model while the risk increased after adjustment. Furthermore, cormobid patients are 1.56 times more likely to develop second cancer than cancer patients without other diseases. Based on the area under the receiver characteristics curve, logistic regression model effectively distinguished between the two groups of cancer patients. Comorbidity and smoking were identified as significant factors on the incidence of second cancer among cancer patients attending UATH. Therefore, emphasis should be given to formulating policies on controlling tobacco smoking and to create health awareness on the effect of clinical factors on second cancer within the study area.

Keywords: Comorbidity, Cancer, Statistical modelling, Sensitivity, Specificity, Odd Ratio

\section{INTRODUCTION}

Cancer is the name given to a group of conditions which causes cells to grow and divide uncontrollably thereby given rise to tumours, impairments and damage immune systems. It is a deadly disease and one of the most commonly diagnosed in recent times. The global rise in cancer is alarming particularly in developing countries where socio-economic conditions are poor and inhabitants' live poverty line (World Bank, 2019). According to the WHO (2018) agency on cancer, the causes of cancer are hereditary factors and other three non-hereditary factors which are: physical carcinogen, chemical carcinogen and biological carcinogen, which has direct connection with lifestyle and genetic background. Some identifiable risk factors of cancer are use of tobacco, excessive alcohol intake, physical inactivity, unhealthy diet and some chronic infections.
Cancer is one of the leading causes of death globally and is responsible for an estimated 8.2 million deaths (WHO, 2018). There are about 32.6 million reported cancer cases globally and 14.1 million new cases documented in literature in 2012 (Salako et al., 2018). Global update in 2018 revealed that there were about 18.1 million new cases with about 9.6 million deaths (WHO, 2018). Following this trend, an estimated 16 million new cases per annum are expected in 2020 with over $70 \%$ of these cases expected from developing countries (Sowunmi et al., 2018). In Nigeria, the available records revealed that about 100,000 new cases of cancer occur every year with a high case fatality ratio. The aged standardized incidence rate of 58.3/100,000 men and 138.6/100,000 women were reported inthe Abuja cancer registry (Jedy-Agba et al., 2012; Sowunmi et al., 2018). This increased cancer 


\section{Oguntade and Oladimeji: Statistical Modelling of Comorbidity Effect on Second Cancer}

burden in recent times in Sub-Saharan Africa (SSA) and especially Nigeria constitutes health problems for the inhabitants and the government. These problems are enormous due to the comorbidity effects of other illnesses and conditions as over $70 \%$ of cancer cases have at least one comorbidity (Bellizzi and Rowland, 2007). These comorbidities, however, have made treatment of cancer patients extremely difficult with negative impact on patients' survival and quality of life.

Comorbidities can be defined as medical illnesses unconnected in aetiology or causality to the major diagnosis that co-occur with the illness of interest (Bjorgul et al., 2010). It is the cooccurrence of two or more disorders in the same individual at the same point in time with a primary condition. It is imperative to recognise the comorbidities of the patient, because they may interrupt diagnosis, change treatment, lead to complications, influence survival, and confound analysis of outcomes (Bjorgul et al., 2010). Cancer patients are likely to be comorbid which could complicate treatment and broaden management (Pule et al., 2019). Patient comorbidity has a significant influence on cancer stage at diagnosis; however, this influence varies significantly by cancer type (Gurney et al., 2015). Severe comorbidity may affect life expectancy and limiting diagnostic investigation (Salako et al., 2018). Studies have identified cardiovascular disease, hypertension, asthma and diabetes to behighly prevalent with cancer of the breast, cervical, prostate and colorectal cancer in Nigeria (Giovannucci et al., 2010; Maiyaki and Garbati, 2014).

Second cancer is a new cancer that occurs in someone who had history of cancer. It is often a new type of cancer different from the first.Causes of second cancer is not always clear; it may result from the same causative agent as the first while others may be caused by cancer treatments (American Cancer Society, (ACS), 2019) though the risk of developinga second cancer due to chemotherapy of the first cancer is rare.
According to national comprehension cancer network (NCCN), there are set of patients that may likely stand the risk of second unrelated cancer due to some health related factors, which include patients who have cancer before 15 years (childhood cancer), immunodeficiency and medicine, aging and hormonal related issues (NCCN, 2020). Other identifiable risk factors could be genetic, left-over of cancer after treatment, smoking, use of alcohol, unhealthy diet, chronic infection, physical inactivity amongst others (Abdelrahman, 2010; Sharp et al., 2014).

Studies on the impact of comorbidities on second cancer occurrence in Nigeria are scarce and such information can influence diagnosis, prognosis, treatment outcomes and survival probability of first cancer occurrence. It is imperative therefore, to assess the effect of comorbidities on second cancer occurrence to address paucity of information on the effect of comorbidity on second cancer in Nigeria. Therefore, this study explores the comorbidity effect on second cancer using a binary logistic regression model (LRM).

\section{MATERIALS AND METHODS Data Collection}

Data of 474 patients were obtained for this study from hospital based cancer register of patients attending University of Abuja Teaching Hospital (UATH), Abuja Nigeria, for primary diagnosis and treatment. Relevant data were collected as secondary data from cancer registry of UATH. Data collected include demographic data such as information on age at diagnosis, sex, marital status, smoking history, educational background, area of residence and clinical status which is comorbidity.

\section{Description and Coding of Variables}

Table 1 presents the coding of variables that were used for this study.

\section{Data presentation}

Descriptive statistics such as mean and standard deviation were adopted to describe continuous variable while frequency and percentage were 


\section{Nigerian Journal of Basic and Applied Science (June, 2020), 28(1): 85-92}

done to describe categorical variables. Also, cross-tabulation was performed to ascertain association between the second cancer occurrence and explanatory variables.

\section{Logistic Regression Model}

Logistic regression model is a statistical tool for modelling a binary dependent variable with one or more independent variables. It is a generalized linear regression model which uses logit as link function for the transformation of the model components. This study adopted LRM due to the fact that the response variable is dichotomous and LRM easily handles continuous covariates without discretization (Oguntade, 2018). Similarly, LRM was explored to examine the association between second cancer occurrence and sociodemographic characteristics, lifestyle and comorbidity status of cancer patients attending UATH.

Let $\mathrm{P}\left(\mathrm{x}_{\mathrm{i}}\right)$ represents the probability of an event for the subject $i, x_{i}$ are the vectors of random variables and the response variable denoted by $y$ assumes values zero when there is nonoccurrence and one when there is second cancer occurrence. The proposed model for this study is defined as:

Logit $(P)=\log [P(x) / 1-P(x)]=\beta_{0}+\beta_{1} X_{\text {age }}+\beta_{2} X_{\text {gender }}+\beta_{3} X_{\text {comorbidity }}+\beta_{4} X_{\text {smoking }}+\beta_{5} X_{\text {marital status }}+\beta_{6} X_{\text {Area }}$ $\beta_{7} X_{\text {Educational } B / G}$

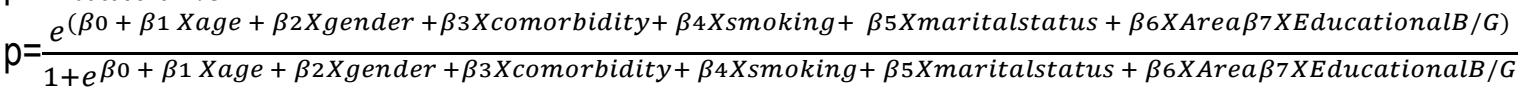

Table 1: Description of explanatory variables, codes and citations from related studies

\begin{tabular}{|c|c|c|c|}
\hline Variables & Codes & Description & Sources \\
\hline $\begin{array}{l}\text { Age at first } \\
\text { diagnosis }\end{array}$ & Quantitative & $\begin{array}{l}\text { Older age increases the chances } \\
\text { of second cancer } \\
\text { Immunosenescene sets in with } \\
\text { advanced in age }\end{array}$ & $\begin{array}{l}\text { Castelo-Brancoand } \\
\text { Soveral (2014); Salako } \\
\text { et al. (2018) }\end{array}$ \\
\hline Gender & $\begin{array}{l}1 \text { Male } \\
0 \text { Female }\end{array}$ & $\begin{array}{l}\text { Male increases the chance of } \\
\text { cancer }\end{array}$ & $\begin{array}{l}\text { Kim et al. (2018);Tevfik } \\
\text { et al. (2012) }\end{array}$ \\
\hline Comorbidity & $\begin{array}{l}1 \text { Present } \\
0 \text { Absent }\end{array}$ & $\begin{array}{l}\text { Presence of secondary condition } \\
\text { increases the likelihood of second } \\
\text { cancer }\end{array}$ & Salako et al. (2018) \\
\hline Marital status & $\begin{array}{l}1 \text { Married } \\
0 \text { Single }\end{array}$ & $\begin{array}{l}\text { Married subjects has a decreased } \\
\text { tendency of second cancer }\end{array}$ & $\begin{array}{l}\text { Swanson et al. (1985); } \\
\text { Kato et al. (1989) }\end{array}$ \\
\hline $\begin{array}{l}\text { Area of } \\
\text { Residence }\end{array}$ & $\begin{array}{l}1 \text { Urban } \\
0 \text { Rural }\end{array}$ & $\begin{array}{l}\text { Living in urban area has an } \\
\text { increased probability of second } \\
\text { cancer }\end{array}$ & $\begin{array}{l}\text { Sharp et al.(2014); } \\
\text { Meilleur et al. (2013) }\end{array}$ \\
\hline Education & $\begin{array}{l}1 \text { Educated } \\
0 \text { llliterate }\end{array}$ & $\begin{array}{l}\text { Literacy decreases the chance of } \\
\text { cancer }\end{array}$ & $\begin{array}{l}\text { Mouw et al (2008); } \\
\text { Leuven et al. (2016) }\end{array}$ \\
\hline
\end{tabular}

Crude odd ratio method was used to ascertain individual strength of association using simple LRM while the partial adjusted or multiple LRM was performed to determine the true strength of association among the studied covariates. The classification accuracy was examined with the Receiver Operating characteristic (ROC). This showed the trade-off between the correct 


\section{Oguntade and Oladimeji: Statistical Modelling of Comorbidity Effect on Second Cancer}

classification of those that have second cancer (true positive rate) and incorrect classification of those that have second cancer (false positive rate). This was done with the plot of the probability of detecting true patients with second cancer (sensitivity) and false patients with second cancer (1-specificity) for the entire range of possible cut off points. The area under the curve revealed the average sensitivity over possible specificities for evaluation of the performance of the classifier. The closer the value of the area under the curve to $100 \%$, the larger the sensitivity and also the specificity values, and hence, the better the performance of the classification test or function.

\section{Ethical Consideration}

The data for this study were exclusively information about anonymous human subjects from UATH. Approval was obtained from UATH prior to the commencement of this study.

\section{RESULTS}

It was observed that out of 474 patients, 191(40.3\%) were male while $283(59.7 \%)$ were females. The distribution of the result by area of residence showed that $151(31.9 \%)$ were rural dwellers while $323(68.1 \%)$ live in urban area. $17.3 \%$ were single and $82.7 \%$ were married, $33.1 \%$ of the patients have history of smoking while $66.9 \%$ were never smoked. The result by education background showed that $41.4 \%$ were never been to school and cannot read and write while $58.6 \%$ were educated (had at least primary education). In term of comorbidity status, 196 $(41.4 \%)$ have other disease(s) apart from cancer and $278(58.6 \%)$ do have only cancer. The second cancer status showed that $39.5 \%$ have second cancer while the remaining $60.5 \%$ do not have second cancer (Table 2).

Table 2: Demographic characteristics and medical history of cancer patients attending UATH

\begin{tabular}{lll}
\hline Variables & Frequency & $\%$ \\
\hline Gender &
\end{tabular}

\begin{tabular}{lcc} 
Male & 191 & 40.3 \\
Female & 283 & 59.7 \\
\hline Residential Area & & \\
Rural & 151 & 31.9 \\
Urban & 323 & 68.1 \\
\hline Marital Status & & \\
Single & 82 & 17.3 \\
Married & 392 & 82.7 \\
\hline Smoking Status & & \\
Yes & 157 & 33.1 \\
No & 317 & 66.9 \\
\hline Education & & \\
Not Educated & 196 & 41.4 \\
Educated & 278 & 58.6 \\
\hline Comorbidity & & \\
Status & & \\
Yes & 196 & 41.4 \\
No & 278 & 58.6 \\
\hline Second Cancer Status & & \\
Yes & 187 & 39.5 \\
No & 286 & 60.5 \\
\hline
\end{tabular}

Table 3 shows that male patients that have second cancer is $51.1 \%$, while $31.8 \%$ of all the females had second cancer, $40 \%$ of rural dwellers had second cancer, $39.3 \%$ those that live in urban had second cancer, $40.2 \%$ of single had second cancer, $39.4 \%$ of those that married had second cancer, $41.5 \%$ of illiterate patients had second cancer, $36.7 \%$ of educated patients had second cancer, $44.4 \%$ of patients that had one or more other disease(s) had second cancer while $36.1 \%$ of patients that had only cancer had second cancer.

Table 3: Cross-tabulation of studiedcovariates and second cancer occurrence among cancer patients attending UATH

\begin{tabular}{lll}
\hline Variable & \multicolumn{2}{l}{ Second Cancer Status } \\
\hline Gender & Yes (\%) & No (\%) \\
Male & $97(51.1)$ & $93(48.9)$ \\
Female & $90(31.8)$ & $193(68.2)$
\end{tabular}

Area of 


\begin{tabular}{lll}
$\begin{array}{lll}\text { Residence } \\
\text { Rural }\end{array}$ & $60(40)$ & $90(60)$ \\
Urban & $127(39.3)$ & $196(60.7)$ \\
$\begin{array}{l}\text { Marital status } \\
\text { Single }\end{array}$ & $33(40.2)$ & $49(59.8)$ \\
Married & $154(39.4)$ & $237(60.6)$ \\
Smoking & & \\
Yes & $94(59.9)$ & $63(40.1)$ \\
No & $93(29.4)$ & $223(70.6)$ \\
Education & & \\
Background & & \\
Illiterate & $115(41.5)$ & $162(58.5)$ \\
Educated & $72(36.7)$ & $124(63.3)$ \\
Comorbidity & & \\
Yes & $87(44.4)$ & $109(55.6)$ \\
No & $100(36.1)$ & $177(63.9)$ \\
\hline Values in parenthesis are expressed in percentages
\end{tabular}

The cross product ratios (Table 5) revealed that male patients were 2.23 times more likely to develop second cancer; patients with history of smoking were 3.58 times more likely to develop second cancer when no adjustment was made to the model or without any control variable(s). Risk of second cancer reduced among male patients after adjustment for other variables, the risk of second cancer was 4.13 times more likely among the patients with history of smoking. Also, patients who were diagnosed of other disease(s) were 1.56 times more likely to develop second cancer than cancer patients without another disease(s). Marriage reduced the risk of second cancer by $44 \%$. Living in urban area reduced the likelihood of developing second cancer by $11 \%$. The odds for educated to illiterates to develop second cancer are 1.36 (Tables 4, 5).

Table 4: Logistic regression model parameter estimate and its related statistics

\begin{tabular}{|c|c|c|c|c|c|}
\hline Covariates & Coef. & Std.err & $z$ & $p>|z|$ & $(95 \% \mathrm{Cl})$ \\
\hline Gender & -0.90 & 0.21 & -4.27 & 0.001 & $\left(\begin{array}{ll}-1.31 & -0.49)\end{array}\right.$ \\
\hline Age & -0.02 & 0.01 & -3.19 & 0.001 & $\left(\begin{array}{ll}-0.04 & -0.09)\end{array}\right.$ \\
\hline $\begin{array}{l}\text { Area of } \\
\text { Residence }\end{array}$ & -0.19 & 0.22 & -0.89 & 0.374 & $(-0.620 .23)$ \\
\hline Marital Status & -0.62 & 0.31 & -1.99 & 0.046 & $(-1.23 \quad-0.01)$ \\
\hline Smoking & 1.35 & 0.21 & 6.37 & 0.001 & $(0.93$ \\
\hline Education & 0.35 & 0.21 & 1.62 & 0.106 & $\left(\begin{array}{lll}-0.07 & 0.76)\end{array}\right.$ \\
\hline Comorbid & 0.20 & 0.20 & 2.04 & 0.041 & $(0.020 .82)$ \\
\hline
\end{tabular}

Coef.: Coefficient; Std err: Standard error; z: z-score; $p>|z|$ : P-value; Cl: Confidence interval

Table 5: Cross product ratioof studied covariates and second cancer occurrence with their associated estimatesamong cancer patients attending UATH.

\begin{tabular}{ccccc}
\hline Variable & $\begin{array}{c}\text { Unadjusted Odds } \\
\text { ratio }\end{array}$ & {$[95 \% \mathrm{Cl}]$} & $\begin{array}{c}\text { Odds } \\
\text { Ratio }\end{array}$ & {$[95 \% \mathrm{Cl}]$} \\
\hline Gender & 2.23 & $(1.53 .33)$ & 0.41 & $(0.27 .62)$ \\
Area of & 1.03 & $(0.691 .56)$ & 0.89 & $(0.581 .40)$ \\
Residence & & $(0.621 .73)$ & 0.56 & $(0.301 .03)$ \\
Marital status & 1.04 & $(2.355 .45)$ & 4.13 & $(2.706 .33)$ \\
Smoking status & 3.58 & $(0.831 .81)$ & 1.36 & $(0.882 .08)$ \\
Education & 1.22 & $(0.962 .08)$ & 1.56 & $(1.032 .34)$ \\
Comorbidity & 1.41 & & &
\end{tabular}

Cl: Confidence Interval 


\section{Oguntade and Oladimeji: Statistical Modelling of Comorbidity Effect on Second Cancer}

\section{Assessment of logistic regression model of second cancer occurrence}

The likelihood ratio test at 0.05 level of significance was highly significant $(G=58.1$, $p<0.001)$, which implies that at least one of the coefficients of the model is different from zero. Table 6 displays the goodness-of-fit statistic which indicated that the model was well fitted.

Table 6: Performance of a classification test of logistic regression model of second cancer occurrence

\begin{tabular}{ll}
\hline Test Statistics & Value \\
\hline Number of Observations & 474 \\
Number of Covariate patterns & 327 \\
Pearson Chi2 & 339.06 \\
Prob chi2 & 0.222 \\
Correctly classified & 67 \\
True D definition as second cancer & 0 \\
Sensitivity $\operatorname{Pr}(+\mathrm{D})$ & $48.7 \%$ \\
Specificity $\operatorname{Pr}(-\mathrm{D})$ & $80.8 \%$ \\
Positive predictive value $\operatorname{Pr}(\mathrm{D}+)$ & $62.3 \%$ \\
Negative predictive value $\operatorname{Pr}(\mathrm{D}-)$ & $70.6 \%$ \\
False+rate for true $\operatorname{DPr}(+\mid \sim \mathrm{D})$ & $19.2 \%$ \\
False-rate for true $\mathrm{D} \operatorname{Pr}(-\mid \mathrm{D})$ & $51.3 \%$ \\
False+rate for classified+ $\operatorname{Pr}(\sim \mathrm{D} \mid+)$ & $37.7 \%$ \\
False-rate for classified- $\operatorname{Pr}(\mathrm{D} \mid-)$ & $29.4 \%$ \\
Correctly classified & $68.1 \%$ \\
\hline
\end{tabular}

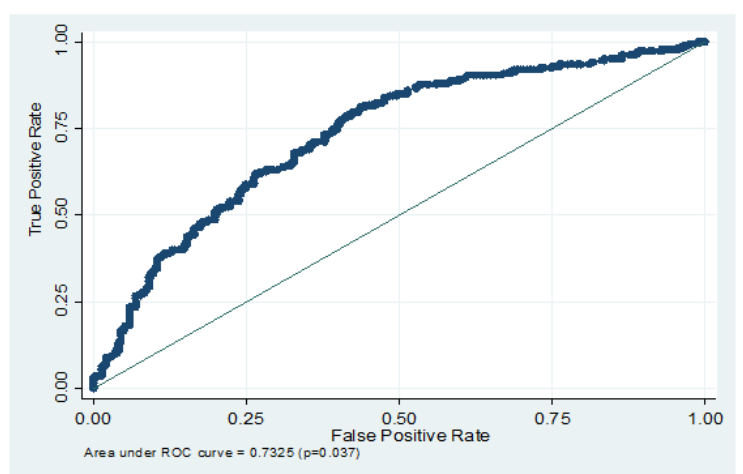

Figure 1: Receiver Operating Characteristics (ROC) curve derived from logistic regression model of second cancer occurrence

\section{DISCUSSION}

This study applied LRM to identify associated risk factors of developing second cancer. The risk factors examined span socio-demographics and clinical risks factors of patients visiting UATH for treatment. These factors include gender, age at first cancer, patient residence, marital status, education status, lifestyle which is history of smoking and the clinical risk factor (comorbidity).

Based on the result of this study, gender, smoking and comorbidity were identified as significant risk factors for second cancer occurrence. This result is in line with a related study in Lagos, Nigeria (Salako et al., 2018). Similarly, this study revealed that the odds ratio of present to absent of other disease(s) ranges between 1.03 times to 2.34 times with $95 \%$ confidence level. This result is consistent with earlier assertion that comorbidity may affect life expectancy and limiting diagnostic investigation (Giovannucci et al., 2010). Furthermore, some comorbid conditions may have a direct effect on cancer growth which invariably may lead to second cancer occurrence. Comorbidity has direct influence on prognosis, treatment outcome and survival probabilities of the patient(s) (Salako et al., 2018). The results of this present study also revealed that age at first cancer was indirectly related to second cancer occurrence. This implies that the earlier a patient developed the first cancer in life, the higher the chance of having a second cancer and vice versa. This is 


\section{Nigerian Journal of Basic and Applied Science (June, 2020), 28(1): 85-92}

consistent with the assertion documented in related literature on incidence of second cancer (Abdelrahman, 2010; ACS, 2019).The authors found that the age of an individual subject at the time of first treatment of cancer has a significant effect on the development of other cancer in the later years.

The area under ROC (Figure 1) indicates that logistic regression has an ability to distinguish between the two groups which support a similar finding in literature (Abdelrahman, 2010). The author noted that logistic regression has low sensitivity because of absent of clinical risk factor which was not considered.

\section{CONCLUSION}

Based on the results of the analyses carried out on the second cancer occurrence, comorbidity and smoking were found to increase the chance of second cancer occurrence within the study area and its environs. Logistic regression model has reasonable sensitivity to distinguish between 'second cancer' and 'no second cancer' groups. Therefore, emphasis should be given to formulating policies on controlling tobacco smoking and to create health awareness on the effect of clinical factors on second cancer occurrence to curb the menace of cancer within the study area and its environs.

\section{ACKNOWLEDGEMENT}

The authors wish to acknowledge the Management of University of Abuja Teaching Hospital for the study data.

\section{REFERENCES}

Abdelrahman, I. (2010). Applying Logistic Regression model to the secondary primary Cancer Data. Department of Statistics, Mathematics and Insurance, Faculty of Commerce, University, Egypt. Retrieved from: interstat.statjournals.net/YEAR/2010/abstra cts/100006 (assessed on 1st October, 2019).

ACS. (2019): What are Second Cancer?
American Cancer Society. Retrieved from www.cancer.org(assessed on 26 th December, 2019).

Bellizzi, K. M., \& Rowland, J. H. (2007). Role of comorbidity, symptoms and age in the health of older survivors following treatment for cancer. Aging Health, 3(5).

Bjorgul, K., Novicoff, W. M.and Saleh, K. J. (2010). Evaluating comorbidities in total hip and knee arthroplasty: available instruments. Journal of Orthopaedics and Traumatology: Official Journal of the Italian Society of Orthopaedics and Traumatology, 11(4): 203-209.

Castelo-Branco, C. and Soveral, I. (2014). The immune system and aging: A review. Gynecological Endocrinology, 30(1): 16-22.

Giovannucci, E., Harlan, D. M., Archer, M. C., Bergenstal, R. M., Gapstur, S. M., Habel, L. A., ... Yee, D. (2010). Diabetes and Cancer: A Consensus Report. Cancer Journal for Clinicians, 60: 207-221.

Gurney, J., Sarfati, D. and Stanley, J. (2015). The impact of patient comorbidity on cancer stage at diagnosis. British Journal of Cancer, 113(9): 1375-1380.

Jedy-Agba, E., Curado, M.P., Ogunbiyi, O., Oga, E., Fabowale T., Igbinoba, F., Osubor G., Otu, T., Kumai, H., Koechlin, A., Osinubi, P., Dakum, P., Blattner, W andAdebamowoC.A. (2012). Cancer Incidence in Nigeria: A Report from Population-based Cancer Registries.Cancer Epidemiology, 36(5): e271-e278.

Kato, I., Tominaga, S. and Terao, C. (1989). An Epidemiological Study on Marital Status and Cancer Incidence. Japanese Journal of Cancer Research, 80: 306-311.

Kim, H. I., Lim, H. and Moon, A. (2018). Sex differences in cancer: Epidemiology, genetics and therapy. Biomolecules and Therapeutics, 26(4): 335-342.

Leuven, E., Plug, E. and Rønning, M. (2016). Education and cancer risk. Labour Economics, 43(777), 106-121. 


\section{Oguntade and Oladimeji: Statistical Modelling of Comorbidity Effect on Second Cancer}

Maiyaki, M. B., \& Garbati, M. A. (2014). The burden of non-communicable diseases in Nigeria; in the context of globalization. Annals of African Medicine, 13(1): 1-10.

Meilleur, A., Subramanian, S. V., Plascak, J. J., Fisher, J. L., Paskett, E. D. and Lamont, E. B. (2013). Rural residence and cancer outcomes in the united states: Issues and challenges. Cancer Epidemiology Biomarkers and Prevention, 22(10): 16571667.

Mouw, T., Koster, A., Wright, M. E., Blank, M. M., Moore, S. C., Hollenbeck, A. and Schatzkin, A. (2008). Education and risk of cancer in a large cohort of men and women in the United States. PLOS ONE, $3(11)$.

NCCN (2020): Understanding your risk of developing secondary cancer, National Comprehensive Cancer Network. Available online

www.nccn.org/patients/resources/life_after cancer/understanding.aspx (Assessed on 22nd April, 2020).

Oguntade E.S. (2018) Determining Malaria Risk Factors in Abuja, Nigeria using Various Statistical Approaches. UPM. Available online:

http://psasir.upm.edu.my/id/eprint/79271/1/

IPM\%202019\%2013\%20IR.pdf (assessed on 16th December, 2019).

Pule, M. L., Buckley, E., Niyonsenga, $T$ and Roder, D. (2019). The effects of comorbidity on colorectal cancer mortality in an Australian cancer population. Scientific Reports, 9(1): 1-10.
Salako, O., Okediji, P. T., Habeebu, M. Y., Fatiregun, O. A., Awofeso, O. M., Okunade, K. S., Oboh, E. O. (2018). The pattern of comorbidities in cancer patients in Lagos, South-Western Nigeria. Ecancermedicalscience, 12: 1-12.

Sharp, L., Donnelly, D., Hegarty, A., Carsin, A. E., Deady, S., McCluskey, N., ... Comber, H. (2014). Risk of several cancers is higher in urban areas after adjusting for socioeconomic status. Results from a twocountry population-based study of 18 common cancers. Journal of Urban Health, 91(3): 510-525.

Swanson, G. M., Belle, S. H. and Satariano, W. A. (1985). Marital Status and Cancer Incidence: Differences in the Black and White Populations. Cancer Research, 45(November): 5883-5889.

Sowunmi, A., Alabi, A., Fatiregun, O.,Olatunji, T.,Okoro, U.S.,Etti, A,F,D.(2018). Trend of Cancer ilncidence in an Oncology Center in Nigeria. West African Journal of Radiology, 25(1): 52-56.

Tevfik Dorak, M. and Karpuzoglu, E. (2012). Gender differences in cancer susceptibility: An inadequately addressed issue. Frontiers in Genetics, 3: 1-11.

WHO (2018): Cancer, World Health Organization. Available online: https://www.who.int/newsroom/fact-sheets/detail/cancer (assessed on $28^{\text {th }}$ December,2019).

World Bank (2019): Understanding Poverty. Retrieved from https://www.worldbank.org (assessed on 26 $6^{\text {th }}$ December, 2019). 